\title{
Importância da produção de mudas para a arborização urbana: viveiros públicos de Teresina, Piauí, Brazil
}

The importance of seedling production for urban afforestation: public nurseries in the city of Teresina, Piauí, Brazil

Importancia de la producción de plántulas para la forestación urbana: viveros públicos en la ciudad de Teresina, Piauí, Brasil

Recebido: 07/01/2022 | Revisado: 12/01/2022 | Aceito: 21/01/2022 | Publicado: 31/01/2022

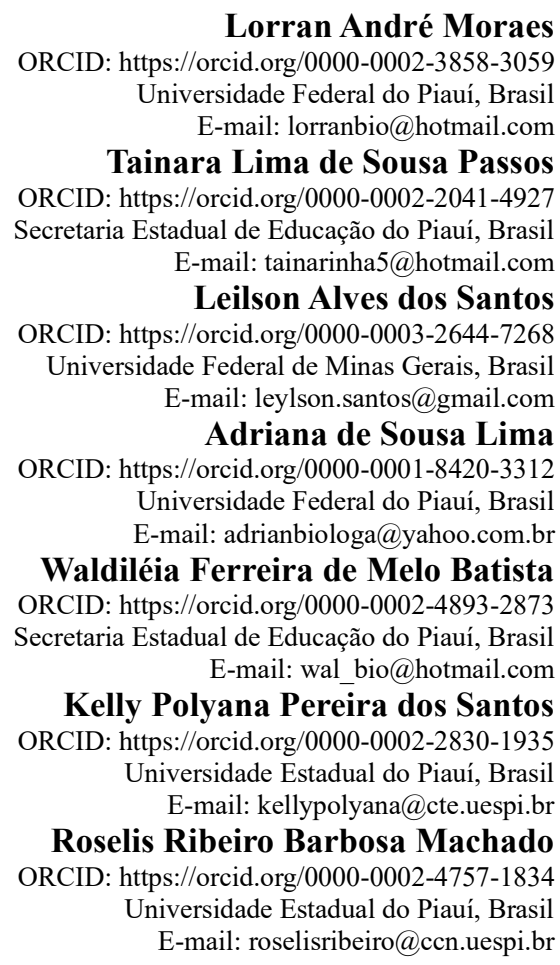

\section{Resumo}

Em face da urbanização, a sociedade tem sido afetada no que diz respeito à qualidade de vida e ao bem-estar. Preservar e integrar espécies vegetais no ambiente urbano tem sido sinônimo de sobrevivência. Dessa forma, os viveiros de mudas se apresentam como elemento essencial para a arborização urbana. Neste sentido, o presente trabalho apresenta informações de dois viveiros de mudas da cidade de Teresina, capital do Piauí, apresentando um diagnóstico acerca de suas dinâmicas, compreendendo como são realizadas cada etapa e fases do processo de coleta, armazenamento e beneficiamento das sementes, produção, manejo, controle, identificação e distribuição das mudas. Apresenta-se, ainda, dados sobre a rotina de produção de mudas e os processos que envolvem desde a coleta das sementes a sua distribuição à população. A abordagem técnica da pesquisa é qualitativa, embasada na pesquisa bibliográfica, de campo e a documental. Nessa pesquisa, observou-se que são produzidas nos viveiros mudas de aproximadamente 80 espécies botânicas. Os resultados demonstram a importância desses locais possuem para a população, a Secretaria de Meio Ambiente e para a comunidade cientifica, sendo ainda, de grande relevância para o planejamento futuro. Portanto, arborizar vai além de plantar mudas em vários lugares, requer planejamento bem gerenciado, assim o conhecimento da dinâmica em viveiros de mudas bem como o repasse dessas informações gera condições de segurança na qualidade e no bem-estar das futuras gerações.

Palavras-chave: Arborização; Qualidade de vida; Viveiros de mudas.

\section{Abstract}

Face to urbanization, society has been affected in terms of quality of life and well-being. Preserving and integrating plant species into the urban environment has been synonymous with survival. In this way "seedling nurseries" are 
"born", whose main objective is urban afforestation with consequent well-being to the population. In this sense, the present study presents information from two seedling nurseries in the capital city of Piaui, presenting a diagnosis about their dynamics, understanding how each stage and phase of the process of collection, storage and processing of seeds, production, management, control, identification and distribution of seedlings are performed. It also presents data about the seedling production routine and the processes that involve from the collection of seeds to their distribution to the population. The technical approach of the research is qualiquantitative, using also the bibliographic, field and documentary research. In this research, it was observed that seedlings of approximately 80 botanical species are produced in nurseries. These results are important data generated by the population, the environmental department and the scientific community, and are also of great relevance for future planning. Therefore, tree planting goes beyond planting seedlings in several places, it requires well managed planning to assume this role, so the knowledge of the dynamics in seedling nurseries as well as the transference of this information generates safety conditions in the quality and welfare of future generations.

Keywords: Arborization; Quality of life; Seedling nurseries.

\section{Resumen}

Debido a la urbanización, la sociedad se ha visto afectada en cuanto a calidad de vida y bienestar. Preservar e integrar especies de plantas en el medio urbano ha sido sinónimo de supervivencia. Así, los viveros de plántulas son un elemento fundamental para la forestación urbana. En este sentido, el presente trabajo presenta información de dos viveros de plántulas en la ciudad de Teresina, capital del estado de Piauí, presentando un diagnóstico de su dinámica, entendiendo cómo se lleva a cabo cada etapa y fases del proceso de recolección, almacenamiento y procesamiento de semillas, producción, manejo, control, identificación y distribución de plántulas. También presenta datos sobre la rutina de producción de plántulas y los procesos involucrados, desde la recolección de semillas hasta su distribución a la población. El enfoque técnico de la investigación es cualitativo, basado en la investigación bibliográfica, de campo y documental. En esta investigación se observó que en los viveros se producen plántulas de aproximadamente 80 especies botánicas. Los resultados demuestran la importancia de estos lugares para la población, el Departamento de Medio Ambiente y para la comunidad científica, siendo también de gran relevancia para la planificación futura. Por tanto, la forestación va más allá de plantar plántulas en diversos lugares, requiere una planificación bien gestionada, por lo que el conocimiento de la dinámica en los viveros de plántulas, así como la transferencia de esta información, genera condiciones de seguridad en la calidad y bienestar de futuras generaciones.

Palabras clave: Forestación; Calidad de vida; Viveros de plántulas.

\section{Introdução}

A urbanização e a industrialização formam um dos principais fatores que contribuem para a deterioração do meio urbano, sendo necessário pensar em estratégias que qualifiquem as cidades para propor bem-estar à população (Robe \& Macedo, 2002; Silva \& Silveira, 2020).

Assim, à medida que o processo de urbanização em face dos reflexos das políticas públicas estabelecidas pelas três esferas governamentais (Federal, Estadual e Municipal) constata-se a diminuição de vegetação natural, afetando de forma intensa o equilíbrio ecológico urbano, contrariando, assim, a qualidade de vida da população (Schuch, 2006). Dessa forma, o homem tem se sensibilizado pela relevância da preservação e integração de espécies vegetais no meio urbano (Schuch, 2006; Panasolo et al., 2014; Souza \& Melo, 2014; Carbone et al., 2015).

A degradação do meio ambiente urbano contribui para o decréscimo da qualidade de vida, resultante de ações antrópicas e da perda relevante de árvores que possuem um fator de suma importância para a vida e ambiente (Rodrigues et al., 2002). As árvores exercem funções ecológica, social, educativa e psicológica no sentido de melhoria do ambiente urbano, e estética, no embelezamento da cidade, na saúde pública, entre outras (Rodrigues et al., 2002; Loboda \& Angelis, 2009; Belmiro et al., 2012; Belmiro et al., 2012; Perehouskei \& Angelis, 2012; Souza \& Melo, 2014; Perehouskei \& Angelis, 2014; Crichyno, 2015; Campos \& Castro, 2017).

Para Rodrigues et al. (2002), uma das soluções para amenizar os problemas causados pela degradação ambiental é implantar no meio urbano a maior porcentagem de vegetação possível, por meio da arborização de vias públicas, praças, margens de cursos d'água e áreas de vertentes íngremes e criação de áreas de preservação, visto a importância das áreas verdes pois assumem um papel de equilíbrio entre os espaços antropizado e o natural. Além disso, segundo Campos e Castro (2017), a relação homem, meio ambiente e saúde é ampla e se projeta sobre a perspectiva de uma melhor qualidade de vida, em especial 
à saúde física e mental da população.

A contribuição da arborização para a melhoria da qualidade ambiental e social, suscitou nas últimas décadas uma quantidade significativa de pesquisas relativas à arborização urbana que vem assumindo cada vez mais destaque no cenário atual das cidades brasileiras (Silva \& Silveira, 2020).

No ambiente das cidades há áreas que precisam de ampliação do verde, em especial os locais que necessitam de recomposição florestal, como as vias públicas, avenidas, bosques, parques, jardins, etc. E, assim, a produção de mudas é uma etapa importante neste processo, sendo um grande aliado à arborização e áreas verdes. As plantas são produzidas, geralmente, em viveiros de mudas, que é uma parcela de terra reservada à produção de plantas e seu manejo até que estejam aptas para serem transportadas, plantadas e adaptadas a condições adversas estabelecendo, assim, um desenvolvimento favorável e, consequentemente alcançando objetivos lucrativos ou não (Oliveira et al., 2005; Scremin-Dias et al., 2006; Oliveira et al., 2016).

Nos viveiros de mudas permeia-se a execução de etapas, estas geralmente acontecem diariamente, tais como: produção, controle de mudas, envolvendo a identificação botânica das espécies, métodos de colheita, beneficiamento e armazenamento de sementes, mecanismos de dormência e germinação de sementes, embalagens, substrato, manejo, bem como a distribuição de mudas. O desenvolvimento destas etapas é complexo devido a pouca informação científica existente sobre este assunto (VásquezYanes \& Orozco-Segovia, 1993; Zamith \& Scarano, 2002; Oliveira et al., 2005; Scremin-Dias et al., 2006; Oliveira et al., 2016).

Nesse contexto, Rodrigues et al. (2002) argumentam que para a composição do verde urbano a escolha da espécie é a etapa mais importante, pois a partir dela analisa-se o espaço disponível que se tem, a presença ou ausência de fiação aérea e de outros equipamentos urbanos, largura da calçada e recuo predial. Ademais, os autores afirmam que dependendo desse espaço, a escolha ficará vinculada ao conhecimento do porte e das características morfológicas da espécie a ser utilizada.

Além disso, é consenso entre os pesquisadores que não basta apenas plantar árvores no meio urbano é necessário conhecer uma série de procedimentos, técnicas, manejo, manutenção, entre outros, tanto em relação a produção de mudas quanto ao plantio e condução das mesmas em novas áreas (Silva \& Silveira, 2020). Por conta da deficiência e/ou usos de alguns desses elementos Gonçalves et al. (2004) afirmam que, em geral, a arborização das cidades brasileiras não tem um planejamento prévio, daí a decorrência de sérios problemas de manejo. Para os autores, isso decorre por que arborizar é uma atividade onerosa e, portanto, requer um planejamento adequado, para evitar correções futuras. E nesse interim o plantio de árvores não pode ser realizado de forma amadorística, há a necessidade de conhecimento amplo e técnico, envolvendo avaliações estética, ecológica, psicológica, social, econômica e política.

Nesse contexto, a cidade de Teresina - PI nas últimas décadas vem sofrendo com o crescimento populacional demasiado, estando esse diretamente relacionado ao aumento de demandas por mais recursos da natureza, ocupação de novas áreas, resultando em degradação de regiões naturais e, consequentemente, acarretando ao meio ambiente o aumento da temperatura (Viana \& Lima, 2017), fazendo-se necessária e urgente a ampliação de sua arborização urbana. Devido a esses fatores, em 2012, criou- se o Programa "Teresina Mais Verde" através do decreto municipal que instituiu o Comitê Operacional do programa de arborização urbana de Teresina. O programa tinha dentre seus objetivos recuperar o título de "cidade verde" para a capital piauiense, através do plantio, replantio e distribuição de mudas de árvores nativas, frutíferas e ornamentais na cidade, a meta totalizou 150 mil exemplares.

Cabe destacar que a arborização urbana e as áreas verdes de uma região podem se iniciar com custos baixos. Nesse sentido, a Secretaria Municipal de Meio Ambiente e Recursos Hídricos (SEMAM) mantém dois viveiros sem fins lucrativos na zona urbana de Teresina -PI, um na zona Leste (Viveiro Municipal SDU Leste) e outro na zona Norte da capital (Viveiro de Mudas SDU Centro-Norte), onde são produzidas mudas para composição das áreas verdes e arborização urbana.

Portanto, torna-se essencial a divulgação sobre o trabalho desses órgãos/locais (viveiros), sobretudo com dados à população e à comunidade cientifica, contribuindo com novos conhecimentos (Carbone et al., 2015). Isso corrobora com Bononi 
(2004), quando cita sobre a importância dos viveiros para o desenvolvimento dos mais diversos setores, entre eles, o ambiental que desempenha um papel de grande significado para a vida, tornando sua preservação e conservação essencial para o bem-estar humano.

Dessa forma, o presente artigo apresenta informações de dois Viveiros de Mudas da capital Piauiense, visando realizar o diagnóstico acerca das suas dinâmicas, compreendendo como são realizadas cada etapa e fases do processo de produção e controle de mudas, as coletas, armazenamento e beneficiamento das sementes, a identificação de espécies vegetais, o substrato, a nutrição, o manejo e a distribuição.

\section{Metodologia}

\subsection{Caracterização da área de estudo}

A cidade de Teresina, capital do Piauí, localiza-se na mesorregião Centro-Norte do estado, a 334 km do litoral piauiense, sendo, portanto, a única capital nordestina fora da zona costeira. A cidade é banhada por dois grandes rios, o Rio Parnaíba e o Rio Poti (Lima, 2009). Teresina possui clima tropical semiúmido com duas estações definidas: o período das chuvas ocorre no verão e outono, e o período seco, ocorre no inverno e primavera (Lima, 2009). O centro da cidade localiza-se em uma depressão, e na maior parte da área do município, o relevo é bastante plano, com exceção para a região do bairro Monte Castelo, situado na Zona Sul, onde se verificam as maiores altitudes, e as adjacências dos bairros Satélite e Vila Bandeirante, na Zona Leste, onde existem muitos morros (Albuquerque \& Lopes, 2016).

Teresina é uma das cidades mais quentes do Brasil, chega a apresentar temperaturas que ultrapassam os $40^{\circ} \mathrm{C}$, a capital recebe grande incidência de radiações solares por se encontrar nas proximidades da Linha do Equador (Mendes, 2000). Devido suas altas temperaturas, se faz necessário a abundância de árvores na cidade para amenizar a temperatura e, consequentemente, melhorar a qualidade do ar e do ambiente.

Dessa forma, como base de estudo destaca-se o Viveiro de Mudas da SDU Centro-Norte, situado na Av. Duque de Caxias no bairro Buenos Aires e o Viveiro de Mudas da SDU Leste, situado na Avenida Raul Lopes no bairro Ininga (Figura 1). 
Figura 1. Localização dos Viveiros de Mudas de Teresina - PI. 1 - Viveiro de mudas da SDU Norte e 2 - Viveiro de mudas da SDU Leste.

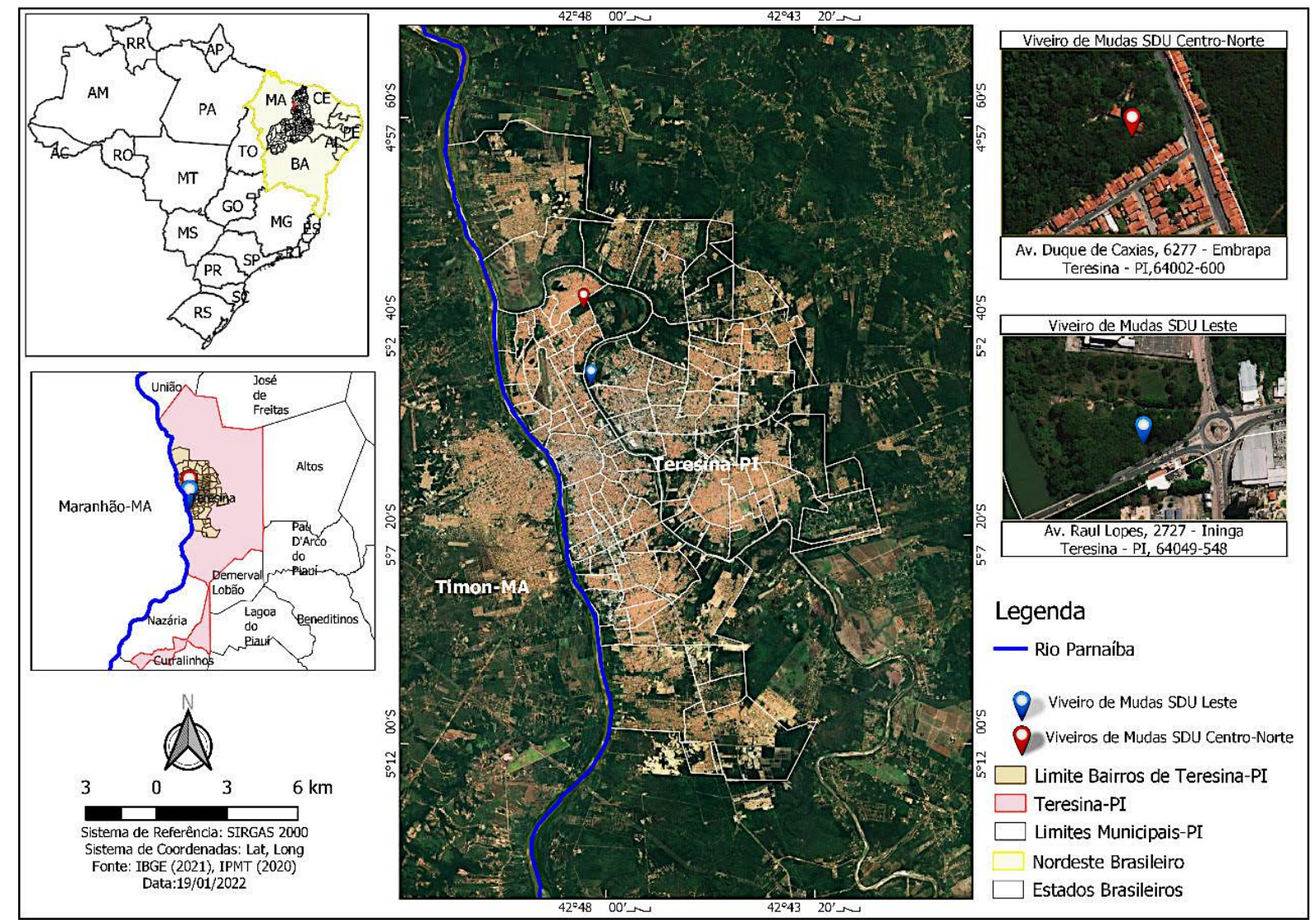

Fonte: IBGE (2021); Google Earth (2021). Organização dos Autores (junho de 2022).

A abordagem técnica da pesquisa é quanti-qualitativa, com seu enfoque na pesquisa qualitativa, usando-se ainda a pesquisa bibliográfica e de campo (Gonsalves, 2001). De acordo com Mussi et al., (2019) a pesquisa quanti-qualitativa é utilizada para o propósito de analisar ou explicar a realidade das diferentes manifestações, dos mais diversos objetos/sujeito e objetivos de pesquisa e, devem ser empregadas em situações específicas que tenham a relação homem-sociedade como foco. Para Gonsalves (2001), a pesquisa de campo é caracterizada pela proximidade do pesquisador com seu objeto de estudo, buscando informações de forma direta com a população pesquisada. Nesse caso, o pesquisador precisa ir ao espaço onde o fenômeno ocorre, a fim de fazer observações e análises que posteriormente serão documentadas e registradas em diário de campo.

Os procedimentos metodológicos desse estudo foram realizados em três etapas com o intuito de melhor sistematizar o andamento da pesquisa, como exposto abaixo:

Primeira etapa: Consistiu em pesquisa bibliográfica baseada em artigos científicos, dissertações e teses, livros e manuais, que abordam a temática (viveiro de mudas e arborização urbana) e a documental (levantamento de dados referentes aos viveiros da cidade de Teresina-PI). Segundo Fonseca (2002), a primeira é feita a partir do levantamento de referências teóricas já analisadas e publicadas por meios escritos e eletrônicos.

Segunda etapa: Foram realizadas visitas in loco de janeiro a maio de 2019 nos Viveiros de Mudas da SDU Leste e no Viveiro de Mudas da SDU Centro-Norte, no intuito de receber a autorização expedida pelo secretáriolcoordenador para coleta e utilização de dados, bem como conhecer as instalações e todo o processo de produção das mudas. após autorização dos representantes, foram aplicados formulários semiestruturados (Bernard, 1988) aos coordenadores e os funcionários mais antigos de ambos os viveiros com o objetivo de adquirir mais informações sobre a dinâmica e funcionamento desses espaços. Houve também conversas informais registradas em diário de campo e registro fotográfico. Vale destacar que a participação dos 
pesquisados foi facultativa e todos assinaram o Termo de Consentimento Livre e Esclarecido (TCLE) em duas vias, uma pertencente ao pesquisador, e outra ao entrevistado.

O levantamento das espécies foi realizado por meio de visitas exploratórias aos viveiros, com base nas mudas que são produzidas, primeiramente utilizando-se do catálogo de espécies vegetais disponibilizados pela SEMAM, das espécies citadas pelos gestores e trabalhadores/viveiristas e da observação e identificação em campo. Após a listagem das espécies de ambos os viveiros as mesmas foram conferidas, identificadas no local por meio da análise morfológica comparada, em literatura taxonômica especializada e em seguida foi organizada em tabela.

Seguimos a metodologia proposta por Moraes et al. (2021) acerca dos procedimentos e obtenção das informações referente as espécies identificadas. Neste estudo, utilizamos o sistema de classificação taxonômica das angiospermas o Angiosperm Phylogeny Group - APG IV (2016). A grafia dos nomes, a sinonímia e os autores, a distribuição por domínios fitogeográficos $(\mathrm{AM}=$ Amazônia; $\mathrm{CA}=$ Caatinga; $\mathrm{CE}=$ Cerrado; $\mathrm{MA}=$ Mata Atlântica; $\mathrm{PT}=$ Pantanal e $\mathrm{PP}=\mathrm{Pampa})$ das espéciesltaxa das angiospermas foram obtidos consultando-se o Nomenclatural Data Base do Missiouri Botanical Garden Tropicos (www.tropicos.org), o The International Plant Names Index (www.ipni.org) e a Lista online da Flora do Brasil 2020 (Lefb, 2020), disponível para acesso em: (http://floradobrasil.jbrj.gov.br/reflora).

Terceira Etapa: Depois de levantados em campo (in loco), os dados foram analisados e tabulados. Os resultados foram apresentados de forma discursiva, em figuras e tabelas utilizando o software Microsoft Excel 2010 para facilitar a leitura e interpretação das informações e dados. Para análise, utilizou-se a estatística descritiva básica.

\section{Resultados e Discussão}

\subsection{Viveiros e o processo de produção das mudas}

Os Viveiro de Mudas SDU Leste e o Viveiro de Mudas SDU Centro-Norte, objetos desse trabalho, fazem parte do projeto Teresina Mais Verde, que além de plantar as mudas na cidade fazem distribuição gratuita à população. O período de maior procura das mudas pela comunidade é durante os meses de dezembro a março, coincidindo com o período chuvoso na capital piauiense, época essa aproveitada para plantar árvores nas residências. Ambos os viveiros de mudas seguem e estão de acordo com os critérios de aplicação dos parâmetros nacionais estabelecidos para esse tipo de empreendimento. Silva e Moraes (2016) reiteram que para a aplicação e criação de um viveiro de mudas, alguns critérios técnicos têm de ser levados em consideração que quando, ajustados entre si, formarão as condições de um bom desenvolvimento, como por exemplo o local de instalação, que faz toda a diferença para que haja êxito nos objetivos que deseja alcançar.

Os viveiros analisados são do tipo frutícola e florestal, do tipo permanente. O objetivo principal das áreas estudadas, é a produção de mudas nativas, frutíferas e ornamentais para ampliação e manutenção das áreas verdes e arborização urbana da cidade de Teresina-PI. Silva e Moraes (2016) enfatizam que os viveiros também desempenhar função socioambiental, uma vez que identificaram que o viveiro de Mudas SDU Centro-Norte é rotineiramente visitado por escolas (públicas e privadas) e universidades da região com intuito de desenvolverem atividades de educação ambiental, sustentabilidade e arborização relacionadas principalmente ao conhecimento sobre produção, plantio de mudas nativas, frutícolas e ornamentais.

Cabe destacar que a localização de um viveiro deve atender a certos requisitos para proporcionar mudas saudáveis, como ser de fácil acesso, com oferta de água de qualidade e em abundância como também limpeza natural, evitando riscos de contaminações (Oliveira 2006; Scremin-Dias et al., 2006; Borges et al., 2011; Oliveira et al., 2016). Os viveiros estudados se atendem bem aos princípios quanto a esses requisitos, pois quanto à disponibilidade de luz solar está em local de meia-sombra, a qual, segundo Dutra et al. (2012) e Reis et al. (2016) é responsável por uma maior percentagem de sobrevivência das mudas quando comparadas ao tratamento em pleno sol. Além disso, ambos possuem irrigação com água de qualidade com captação de poço tubular, sendo realizado manualmente. A limpeza é realizada de forma adequada, por meio de varrição diariamente e capina. 
Em relação à proteção dos viveiros, ambos os locais são cercados para evitar a invasão de animais e protegidos do vento com a presença de cercas vivas (árvores), não havendo proteção por telas (Figura 2).

Figura 2. Destaque dos viveiros de mudas de Teresina - PI, para o aspecto de meia-sombra em disponibilidade de luz solar. Imagem A: o Viveiro de mudas da SDU Centro-norte. Imagem B: Viveiro de mudas da SDU Leste.

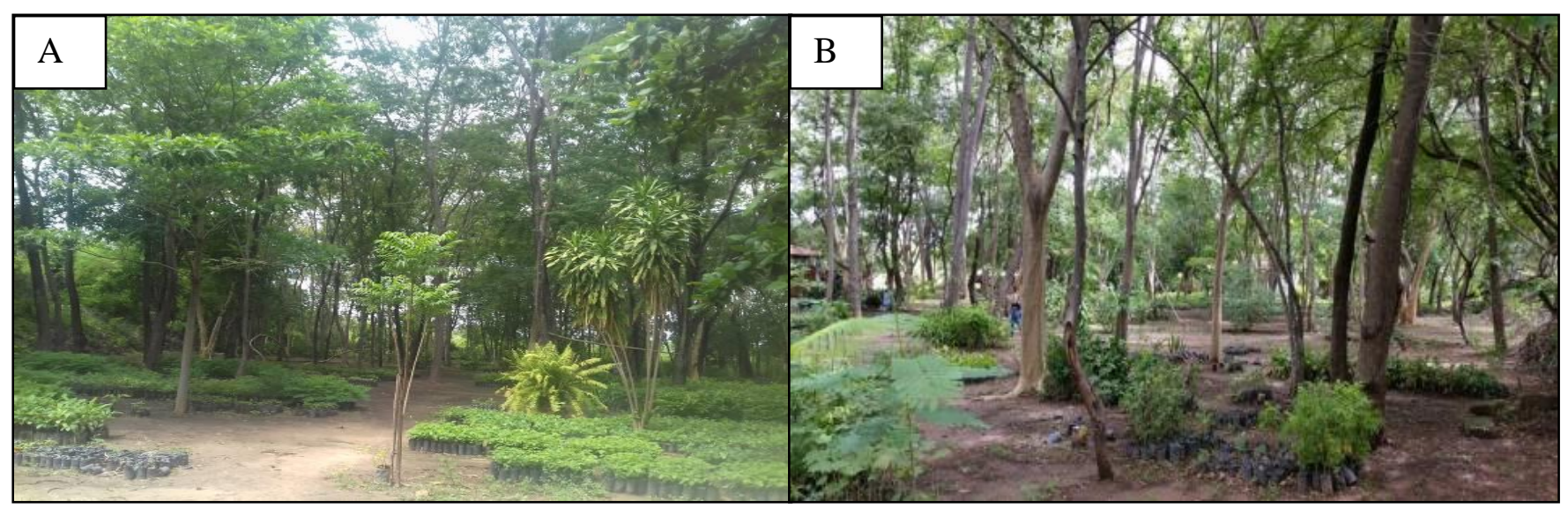

Fonte. Pesquisa direta (fevereiro de 2019).

Quanto ao processo de preparação das sementes para produção das mudas, este é feito pelos funcionários viveiristas de ambos os viveiros, em árvores selecionadas no campo em áreas naturais, como as sedes da Secretaria de Agricultura, Pecuária e Irrigação (SEAPI), Central de Abastecimento do Piauí (CEAPI), Empresa Brasileira de Pesquisa Agropecuária (EMBRAPA), além de doações de entidades, empresas e sítios públicos e privados que trabalham com a matéria-prima (sementes), entre outras áreas naturais. Em campo, a extração da semente é feita de forma manual e tradicional, catando-se as sementes de árvores selecionadas que disponha de boa qualidade, tais como: ausência de pragas, vitalidade, belas formações de copas, além da preferência por plantas nativas, já bem adaptadas ao ambiente, para assim expressarem melhores mudas.

A escolha das espécies em que as sementes serão coletadas, depende da necessidade do viveiro em manter seu banco de semente, da época do ano de frutificação das espécies, da demanda da população e da ampliação das áreas verdes/arborização urbana da cidade. Após a colheita em campo as sementes são selecionadas no viveiro, escolhendo-se como atributos aquelas que apresentam maior vigor e qualidade observável, porém dependendo da necessidade e demanda, nem sempre há esse critério de escolha.

Essa etapa, segundo Oliveira (2006) e Oliveira et al. (2016), é extremamente importante, pois o produtor/viveirista deve ser consciente na escolha da semente e posterior produção das mudas porque o erro nessa operação será mostrado depois de muito tempo podendo causar o insucesso no plantio. Os autores, ainda, citam que é necessário o domínio da técnica de coleta, beneficiamento e armazenamento de sementes e da correta condução da muda para que atinja características desejáveis para o plantio.

Dessa forma, o beneficiamento e a separação das sementes nos viveiros são feitos de forma bem natural (manualmente), seja a separação, seleção, limpeza, ou a secagem, que por sua vez, é feita com a exposição a luz solar. Entretanto, não há um local específico em ambos os viveiros para o armazenamento das sementes. O controle sobre a qualidade, armazenamento e beneficiamento das sementes dos viveiros é feito visualmente sem critério especifico, de forma tradicional, rotineiramente pelos viveiristas.

Em relação ao armazenamento da semente Vilella (2009) cita que, a razão fundamental está vinculada à preservação da qualidade fisiológica e sanitária, pela redução da contaminação por pragas e da incidência de microorganismos e minimização 
da taxa de deterioração. Assim, entende-se que essa etapa é primordial para obtenção de boas mudas, sobretudo quando realizado em grandes quantidades, porém, como a produção nos viveiros pesquisados ocorre em pequena escala e a sua demanda é grande, não há uma necessidade de ocorrer tal etapa, haja vista que tudo que é coletado em campo logo que passa pela seleção ocorre o plantio.

Verificou-se que nos viveiros há algumas construções de canteiros (Figura 3A) destinados para a semeadura. Esses canteiros são um tipo de sementeira e facilitam a produção de mudas quando as sementes são muito pequenas, sendo árdua a distribuição das mesmas individualmente (Macedo, 1993).

Figura 3. Imagem A1 e A2 - Detalhe do formato e estrutura física dos canteiros de mudas dos viveiros de Teresina - PI. Imagem B1 e B2 - Detalhe do enchimento dos recipientes (sacos plásticos) com substratos e do processo de manejo dos sacos para plantio das mudas.

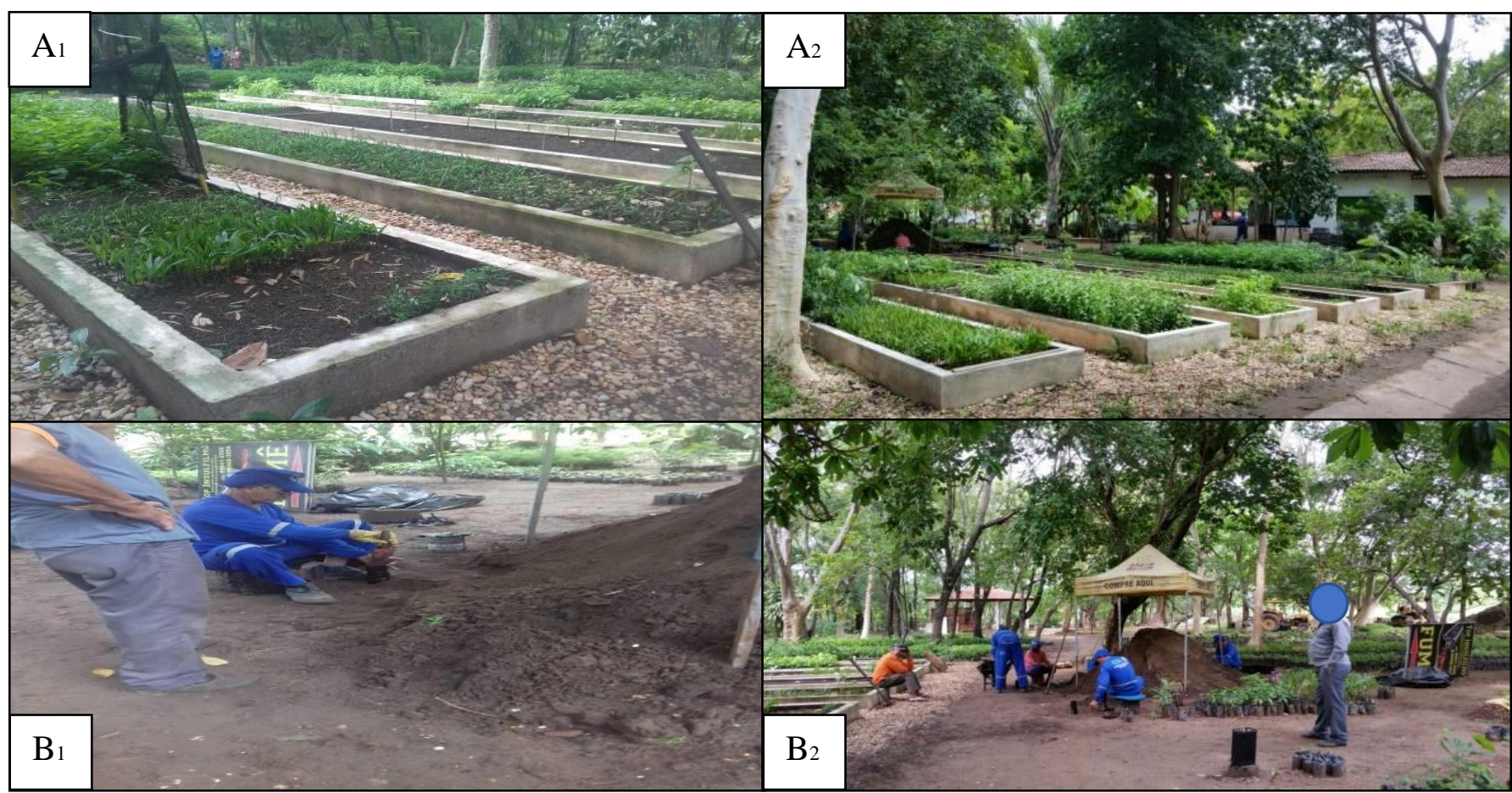

Fonte. Autores (fevereiro de 2019).

Em ambos os viveiros as sementeiras são construídas de alvenaria com semeio indireto, para posterior repicagem, com enchimento dos sacos plásticos pretos adequados com substratos com a finalidade de produção de muda. Em ambos se utiliza terra vegetal e adubo animal na proporção de dois sacos de terra vegetal para dois de adubo animal (Figura 3B). Posteriormente, é feita a transferência das mudas para os recipientes. Em um dos viveiros utiliza-se como recipientes sacos plásticos e tubetes e no outro não há a utilização de tubetes, pois segundo o coordenador esses recipientes prejudicam o desenvolvimento das raízes se ficarem mais tempos nos recipientes. No entanto, Oliveira (2013) cita que os topetes são vantajosos, pois são de fácil manuseio, ocupam menos espaços e dificultam pragas, uma vez que não encostam ao chão e não enovelam as raízes em tempos menores de espera no recipiente.

Em outra etapa, os recipientes (sacos) são preenchidos de substrato manualmente e são posicionados em canteiro por espécie com espaçamentos de aproximadamente $1 \mathrm{~m}$ de largura por $5 \mathrm{~m}$ de extensão, facilitando-se o percurso e manuseio (Figura $4 \mathrm{~A}$ e $4 \mathrm{~B})$. 
Figura 4. A a C: Disposição das mudas em canteiros artificiais nos viveiros segundo e D: tipo de espécie de escolha. E e F: outras formas de disposição das mudas nos viveiros.

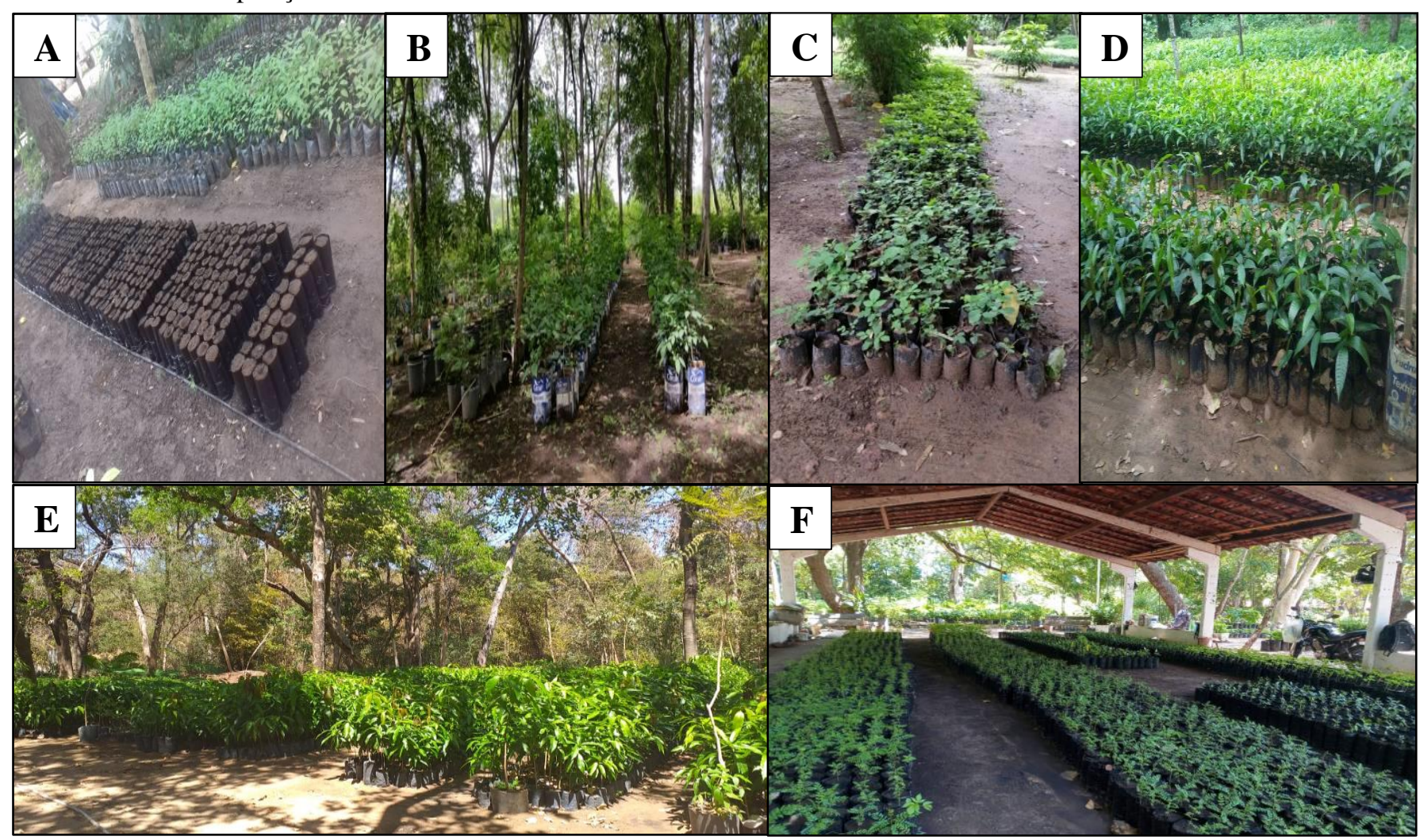

Fonte. Autores (fevereiro de 2019).

Nos viveiros as mudas são produzidas em canteiros específicos, sendo identificadas por espécies. Existe uma setorização artificial para cada espécie, uma forma organizada de classificação das mudas produzidas. Essa identificação é realizada por um funcionário com mais de 10 anos de trabalho em cada viveiro, possuindo conhecimento etnobotânico, proporcionando assim a agilidade na produção, seleção, acondicionamento e distribuição para a população e o meio urbano.

A permanência de uma muda no viveiro, segundo os coordenadores, varia de acordo com a espécie e com a finalidade. As mudas para doação saem a partir de 2 a 6 meses e mudas de espera (para compor as áreas verdes e arborização da cidade) de 2 a 4 anos. Para a distribuição das mudas são observados como critério de saída os parâmetros de controle de qualidade, tais como: altura, diâmetro do colo, bifurcação, retidão do caule, sanidade, coesão do substrato, viscosidade e qualidade da folhagem.

No Viveiro de Mudas da SDU Leste não existe uma lista organizada das mudas produzidas, enquanto que no Viveiro de Mudas SDU Norte existe um catálogo contendo todas as espécies de mudas produzidas com fins de pesquisa. Também foi verificado que não há um controle quantitativo nos viveiros quanto à produção e destinação das mudas. Esses dados, segundo um dos coordenadores, ficam na Secretaria do Meio Ambiente, não sendo disponibilizados diretamente pelos viveiros.

Outro dado constatado são as dificuldades na produção das mudas, no que diz respeito à obtenção de sementes, armazenamento, controle de doenças, pragas ou ervas daninhas, mão de obra, recursos, equipamentos e materiais básicos. Evidenciando-se, a necessidade de investimentos por parte dos órgãos competentes para melhorias dessas repartições públicas.

\subsection{Mudas Produzidas: Florestais, Frutícolas, Nativas e Exóticas}

Grande é a variedade de mudas produzidas em ambos os viveiros, são aproximadamente 84 espécies, distribuídas em 70 gêneros e 28 famílias (Tabela 1). Entre os principais tipos de mudas estão as frutícolas, florestais, nativas e exóticas, as quais 
Research, Society and Development, v. 11, n. 2, e22111225475, 2022

(CC BY 4.0) | ISSN 2525-3409 | DOI: http://dx.doi.org/10.33448/rsd-v11i2.25475

são produzidas em ambos os viveiros com a apropriação adequada à distribuição no meio urbano da cidade de Teresina-PI.

Tabela 1. Lista das espécies de mudas produzidas nos viveiros de Teresina-PI/Brasil, segundo nome popular e científico, família, origem (N - nativa; E - exótica), domínios fitogeográficos (DF) e Indicação/Categoria de uso no meio urbano.

\begin{tabular}{|c|c|c|c|c|}
\hline $\begin{array}{l}\text { Família e Nome cientifico da espécie } \\
\end{array}$ & Nome vulgar & Origem & Domínios fitogeográficos (DF) & $\mathbf{C U}$ \\
\hline \multicolumn{5}{|l|}{ ANACARDIACEAE R.Br. } \\
\hline 1. Anacardium occidentale $\mathrm{L}$. & Caju & $\mathrm{N}$ & $\mathrm{AM}, \mathrm{CA}, \mathrm{CE}, \mathrm{MA}, \mathrm{PA}, \mathrm{PT}$ & 1,7 \\
\hline 2. Astronium fraxinifolium Schott & Gonçalo-Alves & $\mathrm{N}$ & $\mathrm{AM}, \mathrm{CE}, \mathrm{MA}$ & $1,3,4,7$ \\
\hline 3. Astronium urundeuva (M.Allemão) Engl. & Aroeira & $\mathrm{N}$ & CA, CE, MA, PA, PT & 1 \\
\hline 4. $\quad$ Mangifera indica $\mathrm{L}$. & Mangueira & $\mathrm{E}$ & Cultivada & $1,2,7$ \\
\hline 5. $\quad$ Spondias mombin $\mathrm{L}$. & Cajá & $\mathrm{N}$ & $\mathrm{AM}, \mathrm{CE}, \mathrm{MA}$ & $1,2,7$ \\
\hline \multicolumn{5}{|l|}{ ANNONACEAE Juss. } \\
\hline 6. Anona glabra L. & Araticum & $\mathrm{N}$ & AM, MA & 7 \\
\hline 7. Annona muricata $\mathrm{L}$. & Graviola & $\mathrm{E}$ & Cultivada & 7 \\
\hline 8. Annona squamosa $\mathrm{L}$. & Ata & E & Cultivada & 7 \\
\hline \multicolumn{5}{|l|}{ APOCYNACEAE Juss. } \\
\hline 9. Allamanda cathartica $\mathrm{L}$. & Alamanda- amarela & $\mathrm{N}$ & $\mathrm{AM}, \mathrm{CE}, \mathrm{MA}$ & $1,5,6,7$ \\
\hline 10. $\quad$ Plumeria pudica Jacq. & Jasmin-do-caribe & $\mathrm{E}$ & Cultivada & 5 \\
\hline 11. Plumeria rubra L. & Jasmim-manga & E & Cultivada & 6 \\
\hline 12. Thevetia peruviana (Pers.) K.Schum. & Chapéu-de- Napoleão & $\mathrm{N}$ & $\mathrm{AM}, \mathrm{CE}$ & 5 \\
\hline \multicolumn{5}{|l|}{ ARECACEAE Schultz Sch. } \\
\hline 13. Euterpe precatoria Mart. & Açaí & $\mathrm{N}$ & $\mathrm{AM}$ & 7 \\
\hline \multicolumn{5}{|l|}{ BIXACEAE Kunth } \\
\hline 14. Bixa orellana $\mathrm{L}$. & Urucum & $\mathrm{N}$ & $\mathrm{AM}, \mathrm{CE}, \mathrm{MA}$ & 5 \\
\hline \multicolumn{5}{|l|}{ BIGNONIACEAE Juss. } \\
\hline 15. Crescentia cujete $\mathrm{L}$. & Cujuba & $\mathrm{E}$ & Cultivada & 1,3 \\
\hline 16. Handroanthus heptaphyllus (Vell.) Mattos & Ipê-róseo & $\mathrm{N}$ & CE, MA, PP & 3,4 \\
\hline 17. Handroanthus impetiginosus (Mart. ex DC.) Mattos & Ipê-roxo & $\mathrm{N}$ & AM, CA, CE, MA, PP & $1,3,4,7$ \\
\hline 18. Handroanthus serratifolius (Vahl) S.Grose & Ipê-Amarelo & $\mathrm{N}$ & $\mathrm{AM}, \mathrm{CA}, \mathrm{CE}, \mathrm{MA}, \mathrm{PP}$ & $1,3,4,7$ \\
\hline 19. Jacaranda brasiliana (Lam.) Pers. & Caroba & $\mathrm{N}$ & $\mathrm{AM}, \mathrm{CE}$ & $1,3,4,7$ \\
\hline $\begin{array}{l}\text { 20. Tabebuia aurea (Silva Manso) Benth. \& Hook.f. ex } \\
\text { S.Moore }\end{array}$ & Craiba & $\mathrm{N}$ & AM, CA, CE, MA, PT & 1,7 \\
\hline 21. Tabebuia roseoalba (Ridl.) Sandwith & Ipê-branco & $\mathrm{N}$ & CA, CE, MA & $1,3,4$ \\
\hline 22. Tecoma stans (L.) Juss. ex Kunth & Ipêzinho & $\mathrm{N}$ & CE, MA & 5 \\
\hline \multicolumn{5}{|l|}{ BORAGINACEAE Juss. } \\
\hline 23. Cordia goeldiana Huber & Frei Jorge & $\mathrm{N}$ & $\mathrm{AM}$ & $1,2,3$ \\
\hline \multicolumn{5}{|l|}{ CARICACEAE Dumort. } \\
\hline 24. Carica papaya $\mathrm{L}$. & Mamão & E & Cultivada & 1,7 \\
\hline \multicolumn{5}{|l|}{ CAPPARACEAE A. Juss. } \\
\hline 25. Crateva tapia $\mathrm{L}$. & Trapiá & $\mathrm{N}$ & $\mathrm{AM}, \mathrm{CA}, \mathrm{CE}, \mathrm{MA}$ & $1,2,3$ \\
\hline \multicolumn{5}{|l|}{ CHRYSOBALANACEAE R.Br. } \\
\hline 26. Microdesmia rigida (Benth.) Sothers \& Prance & Oiticica & $\mathrm{N}$ & $\mathrm{CA}$ & 1,2 \\
\hline 27. Moquilea tomentosa Benth. & Oiti & $\mathrm{N}$ & MA & $1,3.4,7$ \\
\hline \multicolumn{5}{|l|}{ COMBRETACEAE R.Br. } \\
\hline 28. Terminalia catappa $\mathrm{L}$. & Sombreiro & E & Cultivada & 1,3 \\
\hline 29. Terminalia lucida Hoffmanns. ex Mart. \& Zucc. & Pau-D’água & $\mathrm{N}$ & $\mathrm{AM}, \mathrm{CE}$ & $2,3,7$ \\
\hline \multicolumn{5}{|l|}{ CLUSIACEAE Lindl. } \\
\hline 30. Garcinia gardneriana (Planch. \& Triana) Zappi & Bacupari & $\mathrm{N}$ & AM, CA, CE, MA, PP & 1,7 \\
\hline 31. Platonia insignis Mart. & Bacuri & $\mathrm{N}$ & $\mathrm{AM}, \mathrm{CE}$ & $1,2,3$ \\
\hline \multicolumn{5}{|l|}{ EUPHORBIACEAE Juss. } \\
\hline 32. Jatropha podagrica Hook. & Perna-de-moça & E & Cultivada & 1,5 \\
\hline \multicolumn{5}{|l|}{ FABACEAE Lindl. } \\
\hline 33. Andira fraxinifolia Benth. & Angelim & $\mathrm{N}$ & $\mathrm{CA}, \mathrm{CE}, \mathrm{MA}$ & 1 \\
\hline 34. Anadenanthera colubrina (Vell.) Brenan & Angico Branco & $\mathrm{N}$ & $\mathrm{CA}, \mathrm{CE}, \mathrm{MA}$ & 1,3 \\
\hline 35. Anadenanthera colubrina var. cebil (Griseb.) Altschul & Angico Preto & $\mathrm{N}$ & CA, CE, MA & 1,3 \\
\hline 36. Bauhinia pulchella Benth. & Pata-de-vaca & $\mathrm{N}$ & $\mathrm{AM}, \mathrm{CA}, \mathrm{CE}$ & 1,6 \\
\hline 37. Bauhinia ungulata $\mathrm{L}$. & Mororó & $\mathrm{N}$ & AM, CE, MA & 1,6 \\
\hline 38. Calliandra sessilis Benth. & Sibipiruna & $\mathrm{N}$ & $\mathrm{AM}, \mathrm{CA}, \mathrm{CE}$ & $1,2,3$ \\
\hline 39. Caesalpinia pulcherrima (L.) Sw. & Flamboyanzinho & $\mathrm{E}$ & Cultivada & 1,5 \\
\hline 40. Cenostigma macrophyllum Tul. & Caneleiro & $\mathrm{N}$ & $\mathrm{AM}, \mathrm{CA}, \mathrm{CE}$ & $1,3,4,7$ \\
\hline 41. Cenostigma pyramidale (Tul.) Gagnon \& G.P.Lewis & Sibipiruna do mato & $\mathrm{N}$ & $\mathrm{AM}, \mathrm{CA}$ & $1,2,3$ \\
\hline 42. Clitoria fairchildiana R.A.Howard & Sombreiro & $\mathrm{N}$ & AM, CA, CE, MA & $1,2,3$ \\
\hline 43. Delonix regia (Bojer ex Hook.) Raf. & Flamboyant & $\mathrm{E}$ & Cultivada & 1 \\
\hline Enterolobium contortisiliquum (Vell.) Morong & Tamboril & $\mathrm{N}$ & CA, CE, MA, PP, PT & $1,2,3$ \\
\hline 45. Hymenaea courbaril L. & Jatobá & $\mathrm{N}$ & AM, CA, CE, MA, PT & $1,2,3$ \\
\hline 46. Inga vera Willd. & Ingarana & $\mathrm{N}$ & AM, CE, MA, PP, PT & 1,2 \\
\hline 47. Libidibia ferrea (Mart. ex Tul.) L.P.Queiroz & Jucá & $\mathrm{N}$ & CA, CE, MA & $1,3,4,6,7$ \\
\hline $\begin{array}{l}\text { 48. Martiodendron mediterraneum (Mart. ex Benth.) } \\
\text { R.C.Koeppen }\end{array}$ & Quebra- machado & $\mathrm{N}$ & $\mathrm{AM}, \mathrm{CA}, \mathrm{CE}, \mathrm{MA}$ & $1,2,3$ \\
\hline 49. Parkia platycephala Benth. & Faveira-de-bolota & $\mathrm{N}$ & $\mathrm{AM}, \mathrm{CA}, \mathrm{CE}$ & 1 \\
\hline
\end{tabular}


Research, Society and Development, v. 11, n. 2, e22111225475, 2022

(CC BY 4.0) | ISSN 2525-3409 | DOI: http://dx.doi.org/10.33448/rsd-v11i2.25475

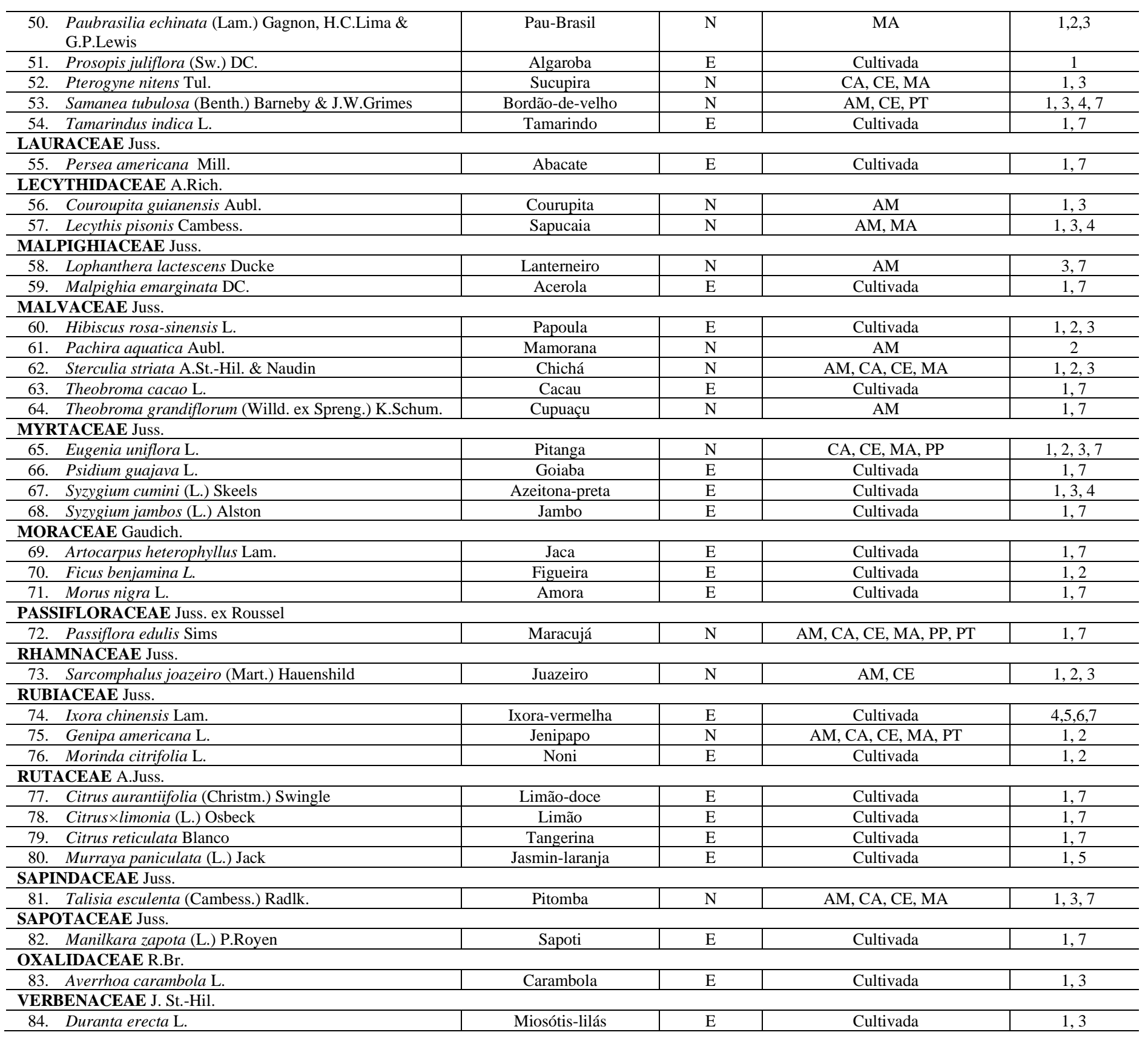

Nota. Origem: Nativa (N) ou exótica (E). Domínios fitogeográficos (DF): Amazônia - AM, Caatinga - CA, Cerrado - CE, Mata Atlântica - MA, Pantanal - PT e Pampas - PP. Indicação/Categoria de uso urbano (CU): 1. Parques/bosques; 2. Parques em margens de rios/córregos; 3. praças/rótulas/balões; 4. Avenidas (canteiro central com no mínimo 1m de largura); 5. Calçada-pequeno porte (mínimo de 1,60m de largura); 6. Calçadas-médio porte (mínimo de 2m de largura); 7. Calçadas - grande porte ( $<5 \mathrm{~m}$ de largura/sem fiação). Fonte: Autores.

As famílias botânicas mais abundantes/frequentes nos viveiros de mudas de Teresina-PI foram: Fabaceae com 22 espécies, Bignoniaceae com 8 espécies, Anacardiaceae e Malvaceae com cinco espécies, Myrtaceae e Rutaceae com quatro espécies, respectivamente. As demais famílias apresentaram entre uma a três espécies.

Das 84 espécies produzidas nos viveiros de mudas de Teresina, 52 espécies $(61,9 \%)$ são de origem nativa, enquanto 28 espécies $(33,3 \%)$ são exóticas. Entre as espécies nativas da região têm-se a A. fraxinifolia (Angelim), A fraxinifolium (Gonçalo Alves), A. colubrina (Angico branco), A. macrocarpa (Angico preto), A. urundeuva (Aroeira), B. pulchella (Pata-de-vaca), B. ungulata (Mororó), C. sessilis (Sibipiruna), C. fairchildiana (Sombreiro), C. macrophyllum (Caneleiro), C. tapia (Trapiá), E. contortisiliquum (Tamboril), Handroanthus sp. (Ipê-amarelo, Ipê-branco, Ipê-rosa e Ipê roxo), H. courbaril (Jatobá), J. brasiliana (Caroba), L. pisonis (Sapucaia), L. ferrea (Jucá), M. rigida (Oiticica), M. tomentosa (Oiti), P. aquatica (Mamorana), 
P. nitens (Sucupira), P. platycephala (Faveira-de-bolota), P. juliflora (Algaroba), S. striata (Chichá), T. aurea (Craiba), T. lucida (Pau-D’água), Terminalia sp. (Pau D’água) e Z. cinnamomum (Juazeiro), dentre outras. Machado et al. (2006) em seu estudo indicam a presença de 48 espécies de árvores nativas da cidade de Teresina-PI com potencial de uso nas várias modalidades de arborização da cidade, das quais todas são produzidas nos viveiros de mudas.

Um dado interessante a ser observado quanto a escolha das espécies nos viveiros pela comunidade e que as espécies frutíferas são mais procuradas. Dentre essas espécies as que apresentam valor alimentício animal e humano em maior destaque, tais como: A. carambola (Carambola), A. heterophyllus (Jaca), A. muricata (Graviola), A. occidentale (Caju), A. squamosa (Ata), C. papaya (Mamão), Citrus sp. (Limão-doce, Limão e Tangerina), E. uniflora (Pitanga), E. precatoria (Açaí), G. americana (Jenipapo), G. gardneriana (Bacupari), M. citrifolia (Noni), M. emarginata (Acerola), M. indica (Mangueira), M. nigra (Amora), M. zapota (Sapoti), P. americana (Abacate), P. edulis (Maracujá), P. guajava (Goiaba), P. insignis (Bacuri), S. cumini (Azeitonapreta), S. jambos (Jambo), S. mombin (Cajá), T. cacao (Cacau), T. esculenta (Pitomba), T. grandiflorum (Cupuaçu), T. indica (Tamarindo), dentre outras. No entanto, segundo Albertin et al., (2011) algumas dessas espécies frutíferas não são recomendadas para a arborização viária, podendo causar alguns problemas à cidade, assim faz-se necessário informar a população sobre a indicação de uso correto da espécie a ser adquirida para plantio.

Apesar de ocorrer produção de mudas constantemente nos viveiros, muitas vezes, a produtividade de determinada espécie é interrompida pelo fato de haver pouca procura, ou por problemas de pragas/doenças que pode levar a contaminação de outras espécies. Além disso, nota-se que essa identificação in locu da espécie pelos viveiristas para a distribuição, faz parte de um manejo adequado, evitando posteriores problemas advindos da falta de planejamento prévio, tais como, conflito de árvores com fiações elétricas, encanamentos, muros, calçadas, construções, etc.

É notório que os viveiros de mudas desempenham importantes funções e contribuições no ambiente urbano, em especial na produção de mudas de espécies florestais, nativas e frutícolas, entre outras. Apesar disso, os viveiros muitas vezes não apresentam um controle eficiente na qualidade das mudas produzidas e que são distribuídas para plantio na zona urbana de Teresina-PI. Nessa pesquisa não foi objetivo realizar essas análises e observações.

Em um estudo realizado por Gonçalves et al., (2004) em diversos viveiros (instituições públicas e particulares) do estado de Minas Gerais para avaliar a qualidade das mudas destinadas à arborização urbana, indicou que, de maneira geral, não há uma preocupação com a qualidade das mudas, fato comprovado pelas altas porcentagens daquelas fora do padrão. Além disso, os autores citam que os problemas que mais contribuem para a baixa qualidade das mudas, tanto em viveiros públicos quanto particulares, são a altura abaixo da recomendada $(1,5 \mathrm{~m})$ e a ausência de podas de condução e de formação. Outra importante observação dos autores é que grande parte dos problemas se deve à falta de treinamento dos funcionários, poucos funcionários e falta de domínio das técnicas silviculturais necessárias à produção das mudas, principalmente em se tratando de viveiros particulares, onde as mudas estão com qualidade inferior às dos viveiros públicos.

\subsection{Produção e Distribuição de mudas nos viveiros}

Em abril de 2010 foi criado pela coordenação de arborização na cidade de Teresina-PI o Programa "Teresina Mais Verde", onde durante a gestão do projeto (2010-2012), alcançou a meta de produzir, plantar, replantar e distribuir 150 mil mudas de árvores nativas, frutíferas e ornamentais (Quadro 1). 
Quadro 1: Produção de mudas dos viveiros de Teresina entre 2010-2017.

\begin{tabular}{|l|l|l|l|l|}
\hline Nome do viveiro & $\begin{array}{l}\text { Projeto } \\
\mathbf{( 2 0 1 0 - 2 0 1 2 )}\end{array}$ & $\begin{array}{l}\mathbf{N}^{\mathbf{0}} \text { de mudas } \\
\text { produzidas em 2017 }\end{array}$ & $\begin{array}{l}\mathbf{N}^{\mathbf{0}} \text { de mudas doadas } \\
\text { em 2017 }\end{array}$ & $\begin{array}{l}\text { Atendimento a } \\
\text { população 2017 }\end{array}$ \\
\hline $\begin{array}{l}\text { Viveiro de mudas } \\
\text { (SDU Centro/Norte) }\end{array}$ & - & 102.384 mudas & 26.383 mudas & 3.388 pessoas \\
\hline $\begin{array}{l}\text { Viveiro de mudas } \\
\text { (SDU Leste) }\end{array}$ & - & 86.190 mudas & 26.001 mudas & 3.158 pessoas \\
\hline $\begin{array}{l}\text { Viveiro de mudas } \\
\text { (SDU Sul) }\end{array}$ & - & Desativado & 4.600 mudas & - \\
\hline TOTAIS & $\begin{array}{l}\text { Aproximadamente } \\
\mathbf{2 7 4} \text { mil mudas } \\
\text { produzidas }\end{array}$ & $\begin{array}{l}\mathbf{1 8 8 . 5 7 4} \text { mudas } \\
\text { produzidas }\end{array}$ & $\mathbf{5 6 . 9 8 4}$ mudas & $\mathbf{6 . 5 4 6}$ atendimentos \\
\hline
\end{tabular}

Fonte: Pesquisa Direta (2019).

Essa ação buscou preservar/conservar o meio ambiente, em especial na tentativa de diminuir a alta temperatura da cidade, ampliando e implementando, ainda, a composição da arborização e das áreas verdes da cidade, em especial das praças, parques, jardins, canteiros centrais de ruas e avenidas. Silva e Moraes (2016) argumentam que o sucesso dessa gestão foi enorme e com a sucessão parlamentar de Teresina - PI durante 2013 a 2016 o programa foi resgatado e a meta foi dobrada sendo plantadas mais 300 mil mudas de abril/2013 a dezembro/2016. No ano de 2017, houve um significativo aumento do número de produção de mudas nos viveiros, a produção chegou a quase 200 mil mudas/ano. Foram 102.384 mudas no viveiro da SDU Norte e 86.190 no viveiro da SDU Leste.

Carvalho, Nogueira e Lemos (2016), destacam a respeito da importância do planejamento urbano integrado junto aos poderes municipal, estadual, universidades, comunidade, as concessionárias de energia elétrica e telefônicas, sistemas de água e esgoto, a fim de minimizar os problemas e impactos que uma arborização mal executada pode acarretar nas cidades.

Além da doação de mudas, a arborização de Teresina também acontece através do plantio de novas árvores em ruas, avenidas, rotatórias, praças, parques, mata ciliar, áreas verdes degradadas, dentro outros. As equipes atuam no início do ano, aproveitando o período chuvoso da capital para melhor desenvolvimento das mudas. Silva e Moraes (2016) acrescentam que o projeto atua de três formas: 1) a prefeitura planta diretamente em praças, parques, canteiros centrais de avenidas, bosques e áreas verdes públicas; 2) em conjunto com associação de moradores, entidades e eventos com a distribuição de mudas; 3) Através da distribuição direta à população nos viveiros municipais.

Em relação às doações de mudas, por exemplo no ano de 2017, foram ofertadas a comunidade quase 60 mil mudas. Números crescentes comparados aos anos anteriores do projeto. Nota-se, portanto, que comparado ao ano de implementação do projeto (2010-2012) o número é menor, ressalvando assim a relevância de constantes projetos de arborização na cidade.

Vale destacar que em setembro de 2019 a prefeitura de Teresina comemorou a marca de 1.000.000.000 (um milhão) de mudas plantadas e distribuídas na cidade nos últimos 12 anos (Figura 5). 
Figura 5. Registro do plantio de mudas e a presença de árvores nas principais avenidas da zona leste da cidade de Teresina, Piauí. A a E: Arborização de um trecho da avenida João XXIII. F: Arborização de um trecho da avenida Presidente Kennedy. G: Arborização de um trecho da avenida Zequinha Freire. H: Arborização de um trecho da avenida Horácio Ribeiro.

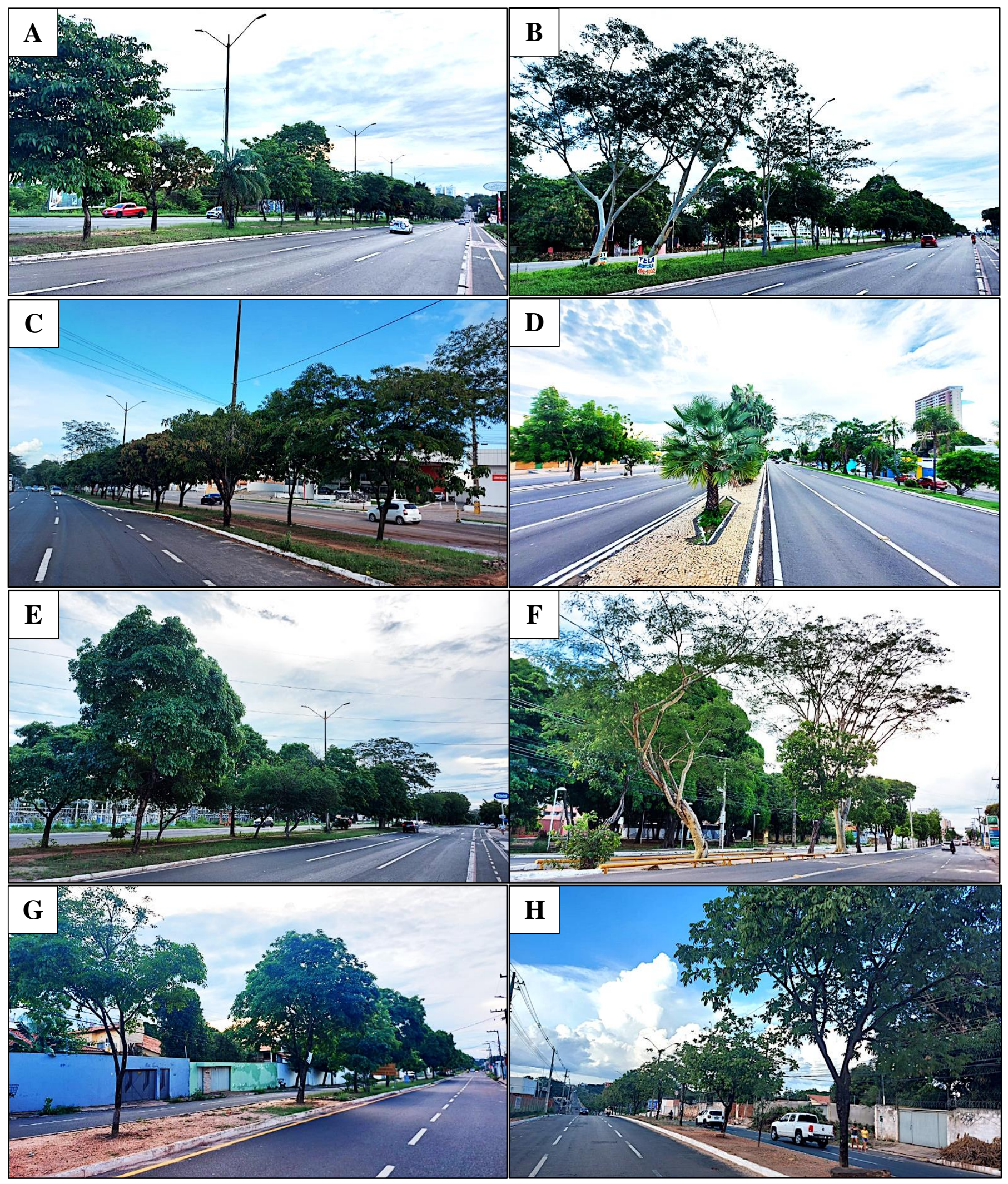

Fonte. Autores (fevereiro de 2019). 


\subsection{Os viveiros e a comunidade urbana: dinâmica e sociabilidade}

Os viveiros foco desse estudo são totalmente abertos à comunidade que participa ativamente de diversas atividades, entre elas: aquisição de mudas, contemplação/visitação, atividades práticas de educação ambiental e de desenvolvimento sustentável, esta última sendo rotineiramente.

Para a comunidade que vai com o intuito de receber mudas, é importante lembrar que estas estão disponíveis em ambos os viveiros (SDU Centro- Norte e SDU-LESTE) e que, dependendo da espécie, a disponibilidade para doação acontece em apenas uma determinada época do ano devido a sazonalidade climática. Outro dado a ser destacado é que quando há uma pequena quantidade de espécies no viveiro da SDU Centro-Norte, este interrompe as doações, enquanto que o viveiro da SDU Leste produz mudas de plantas o ano todo (dependendo da espécie), mantendo-se aberto o ano inteiro.

Ressalta-se, ainda, que qualquer pessoa pode solicitar, de forma gratuita, de uma a dez mudas para plantar em suas casas ou em sítios, auxiliando na recomposição vegetal da cidade. Para a comunidade, recebê-las, faz-se necessário apenas a apresentação do documento de identificação e um comprovante de endereço. Caso a pessoa deseje adquirir mais mudas, basta levar um ofício simples informando a quantidade de mudas que deseja receber, os motivos da aquisição e o local que será realizado o plantio.

Durante a entrega das mudas são repassadas informações e orientações à comunidade por técnicos capacitados, tais como: escolha da muda, adequação ao ambiente, a prática de plantio e os cuidados necessários para a manutenção do vegetal. E, além das distribuições de rotina das mudas nos viveiros para a população, há também a realizada por meio do "caminhão do verde" conhecido como "Projeto itinerante mais verde" que distribuem mudas de plantas nativas e/ou frutíferas periodicamente nos bairros, vilas e conjuntos habitacionais de todas as regiões de Teresina - PI, intensificando também a divulgação sobre a distribuição de mudas pelos órgãos e, consequentemente intensificando a busca de mudas por parte da população.

Há pontos fixos de distribuição de mudas na cidade, em número de três localizados na avenida Raul Lopes, outro na avenida Duque de Caxias e outro no km 7, na BR 316. Essa distribuição à população ocorre também em eventos e ações realizadas pela prefeitura em todas as zonas, ou por meio de solicitação via atendimento telefônico para associação de moradores, colégios e faculdades, intensificando assim a cobertura vegetal da cidade.

Assim, as principais formas de saída das mudas dos viveiros da cidade (doação, projeto caminhão do verde, atendimento por telefone e o plantio pelos técnicos da prefeitura nas áreas verdes e arborização) contribuem para a ampliação e melhoria, do verde urbano da capital, corroborando com o que citam Lima e Amorim (2006), Belmiro et al. (2012), Souza e Melo (2014) sobre a importância das áreas verdes no espaço urbano para a qualidade ambiental das cidades, como também na ampliação da qualidade de vida da população e de seu entorno que necessita desses espaços públicos, seja para passear, praticar esportes e demais atividades recreativas.

Além do bem-estar proporcionado à população, a arborização apresenta também as funções ecológicas, sociais, estéticas, educativas e psicológicas destes locais sendo decisivos para a sustentabilidade urbana em longo prazo, a saúde pública e a humanidade (Loboda \& Angelis, 2009; Belmiro et al., 2012; Perehouskei \& Angelis, 2012; Perehouskei \& Angelis, 2014; Souza \& Melo, 2014; Crichyno, 2015; Campos; Castro 2017). Entretanto, como afirmam Campos e Castro (2017) e Carbone et $a l$. (2015) tais espaços (áreas verdes) atualmente não são valorizados pelos benefícios que podem conferir, sendo negligenciados pelos governos e comunidades em geral.

Para enfatizar a importância e a contribuição dos viveiros de mudas estudados nessa pesquisa, entende-se que estes desempenham importantes funções para a cidade de Teresina, principalmente na arborização urbana que, segundo Rodrigues $e t$ al. (2002), abrange toda cobertura vegetal de porte arbóreo existente nas cidades, logo essas mudas que foram e estão sendo plantadas na cidade de Teresina estão ocupando distintos espaços, em especial as áreas livres de uso público e potencialmente 
coletivas como as praças, parques, bosques, jardins, as áreas livres particulares e/ou acompanhando o sistema viário de ruas e avenidas.

Nesse contexto, Lima e Oliveira-Filho (2020) chamam a atenção quanto a necessidade da realização de pesquisas voltadas a arborização urbana no Nordeste brasileiro, uma vez que para a região há poucos estudos quando comparados com a região sul e sudeste do país. Ademais, os autores acrescentam, ainda, que o acesso e divulgação da informação quanto a arborização contribui para informar os gestores e a comunidade quanto os benefícios ambientais e de bem-estar que a mesma proporciona no ambiente urbano.

Assim, reitera-se a importância da continuação dos projetos, ações e processos realizados pelos viveiros em funcionamento, pois todos esses resultados são frutos das ações e parcerias advindas do empenho da equipe da Secretaria Municipal de Meio Ambiente e Recursos Hídricos (SEMAM) em especial o do Comitê de arborização e do apoio e entusiasmo da comunidade.

\section{Conclusão}

Arborizar uma cidade vai além de plantar mudas em vários lugares, requer planejamento que se inicia na coleta das sementes passando pelo beneficiamento, chegando à produção, controle, manejo e a distribuição de mudas. Constatou-se, ainda, que viveiros de mudas bem gerenciadas assumem com primazia seu papel, como é o caso dos viveiros de Teresina, que mesmo diante de dificuldades na produção, no que diz respeito à obtenção de sementes, armazenamento, controle de doenças, pragas ou ervas daninhas, mão de obra, recursos, equipamentos e materiais básicos, promovem projetos de distribuição e conscientização da população sobre a importância de áreas verdes, além de informar os procedimentos corretos para o bom desenvolvimento das mudas doadas.

Assim, nota-se que trabalhos científicos com a finalidade de transmitir informações à sociedade para a melhoria do meio ambiente, como a presente pesquisa, promoverão bem-estar e qualidade de vida a todos, como também conhecimento sobre a importância das etapas na produção e distribuição de mudas para ambientar a cidade. Portanto, o conhecimento da dinâmica em viveiros de mudas, bem como o repasse dessas informações gera condições de segurança na qualidade e no bem-estar dos presentes e futuras gerações.

\section{Referências}

Albertin, R. M., Angelis, R., Angelis-Neto, G., \& Angelis, B. L. D. (2011). Diagnóstico qualiquantitativo da arborização viária de Nova Esperança, Paraná, BRASIL. Revista da Soc. Bras. Arborização Urbana. 6(3), 128-148.

Albuquerque, M. M., \& Lopes, W. G. R. (2016) Influência da Vegetação em Variáveis Climáticas: estudo em bairros da Cidade de Teresina, Piauí. Revista $R a{ }^{\prime} e G a, 36,38-68$.

APG IV. (2016). An update of the Angiosperm Phylogeny Group classification for the orders and families of flowering plants: APG IV. Botanical Journal of the Linnean Society, 181, 1-20. https://doi.org/10.1111/boj.12385.

Barbosa, R. R. (2008). Gestão da informação e do conhecimento: origens, polêmicas e perspectivas. Informação \& Informação, Londrina, 13, 1-25.

Belmiro, A., Cristina, B., Felisberto, C., Batista, D., Orlando, D., \& Pereira, R. (2012). Área verde benefícios para a humanidade, saúde pública e qualidade de vida. Revista educação ambiental em ação, 20(43), 1-10.

Bernard, H. R. (1988). Research Methods in Cultural Anthropology. Sage. Newbury Park, CA, EEUU. 520p.

Bononi, V. L. R. (2004). Controle ambiental de áreas verdes. In: Philippi, Jr. A. et al. (Org.). Curso de Gestão Ambiental. Manole.

Borges, J. D. et al. (2007). Viveiros florestais: projeto, instalação, manejo e comercialização. Brasília: Rede de Sementes do Cerrado.

Cabral, I. D. (2013). Arborização Urbana: problemas e benefícios. Revista Especialize, 6(1), 1-15. http://www.ipog.edu.br/uploads/arquivos/3474154c808305a9ba984df5faa037c2.pdf.

Campos, R. B. F., \& Castro, J. M. (2017). Áreas Verdes: Espaços Urbanos Negligenciados Impactando a Saúde. Sau. \& Transf. Soc., 8(1), 106-116. 
Carbone, A. S., Coutinho, S. M. V., Tomerius, S., \& Philippi-Junior, A. (2015). Gestão de áreas verdes no município de São Paulo: Ganhos e limites. Ambiente \& Sociedade, 18(4), 201-220.

Carneiro, J. G. A. (1995). Produção e controle de qualidade de mudas florestais. Curitiba, UFPR/FUPEF; Folha de Viçosa.

Carvalho, L. A., Nogueira, J. F., \& Lemos, J. R. (2016). Inventário da Arborização de um Bairro da cidade de Parnaíba - Piauí, com utilização de um Sistema de Informação Geográfico. Revista da Casa de Geografia de Sobral, 18(1), 100-117.

Cecchetto, C. T., Christma, N. N, S. S., \& Oliveira, T. D. (2018). Arborização Urbana: importância e benefícios no planejamento ambiental das cidades. Anais. In: XVI Seminário Internacional de Educação do Mercosul.

Choo, C. W. (2006). A organização do conhecimento: como as organizações usam a informação para criar significado, construir conhecimento e tomar decisões. (2a ed.), SENAC.

Cidade Verde. Prefeitura alcança marca de um milhão de mudas plantadas em Teresina. (2019). https://cidadeverde.com/noticias/309177/prefeitura-alcancamarca-de-um-milhao-de-mudas-plantadas-em-teresina.

Cuiabália, C. et al. (2011). Pesquisa Quali-Quanti. Programa em Ciência Ambiental. Universidade de São Paulo.

Dutra, T. R., Grazziotti, P. H., Santana, R. C., \& Massad, M. D. (2012). Desenvolvimento inicial de mudas de copaíba sob diferentes níveis de sombreamento e substratos. Revista Ciência Agronômica, Fortaleza-CE, 43(2), 321-329.

Gonçalves, E. O. et al. (2004). Avaliação qualitativa de mudas destinadas à arborização urbana no estado de Minas Gerais. R. Árvore, Viçosa-MG, 28(4), 479486.

Gonsalves, E. P. (1999). Métodos e Técnicas da Pesquisa Social. (5a ed.), Atlas.

Lima, I. M. M. (2009). Teresina-cidade verde. Ed. Cortez.

Lima, J. R., \& Oliveira Filho, L. S. (2020). Publicações sobre arborização urbana na região nordeste, Brasil. Revsbau, 15(3), 56-69.

Lima, V., \& AMORIM, M. C. C. T. (2006). A importância das áreas verdes para a qualidade ambiental das cidades. Revista Formação, $13,139-165$.

Loboda, C. R., \& Angelis, B. L. D. (2009). Áreas verdes públicas urbanas: conceitos, usos e funções. Ambiência, 1(1), 125-39.

Macedo, A. C. (1993). Produção de Mudas em Viveiros florestais espécies nativas. Fundação Florestal. 18p.

Machado, R. R. B. et al. (2006). Árvores nativas para a arborização de Teresina, Piauí. Revsbau, 1(1), 10-18.

Mendes, Silvano. (2000). Teresina é uma das cidades mais quentes do Brasil. Diário do Grande ABC. http:// www.dgac.com.br>mobile>teresina-e-uma-dascidades-mais-quentes-do-brasil.

Moura, I. R. (2010). Arborização urbana: estudo das praças do bairro centro de Teresina. 2010. 127f. Dissertação (mestrado) - Universidade Estadual Paulista, Instituto de Geociências e Ciências Exatas.

Moraes, L. A., Araújo, M. F. V., \& Conceição, G. M. (2021). Levantamento florístico das angiospermas do Parque Estadual Cânion do rio Poti, Buriti dos Montes - PI. Revista Brasileira de Geografia Física, 14, 4, 1987-2014, 2021. 10.26848/rbgf.v14.4.p1987-2014.

Mussi, R. F. F., Mussi, L. M. T., Assunção, E. T. C., \& Nunes, C. P. (2019). Pesquisa Quantitativa e/ou Qualitativa: distanciamentos, aproximações e possibilidades. Revista Sustineire, Rio de Janeiro, 7, 414-430.

Oliveira, M. C. et al. (2005). Viveiros e produção de mudas de algumas espécies arbóreas nativa do cerrado. Embrapa Cerrados

Oliveira, M. C. et al. (2016). Manual de viveiro e produção de mudas: espécies arbóreas nativas do Cerrado. Editora Rede de Sementes do Cerrado.

Pagliari, S. C. et al. (2013). Arborização urbana: importância das espécies adequadas. http://editora.unoesc.edu.br/index.php/acet/ article/download/1083/pdf_2.

Panasolo, A. et al. (2014). Áreas verdes urbanas privadas de Curitiba: uma proposta de valorização para conservação (estudo de caso). Enciclopédia Biosfera, Centro Científico Conhecer - Goiânia, 10(19), 2731-44.

Perehouskei, N. A., \& Angelis, B. L. D. (2012). Áreas verdes e saúde: paradigmas e experiências. Diálogos \& Saberes, 8(1), 55-77.

Perehouskei, N. A., \& Angelis, B. L. D. (2014). A influência das áreas verdes nos serviços públicos de saúde na cidade de Mandaguari, Paraná, Brasil. Jornal Health Biol Sci., 2(2), 74-83.

Philippi Júnior., A., Romero, M. A., \& Bruna, G. C. (2014). Curso de Gestão Ambiental. Barueri - SP: Manole.

Prefeitura de Teresina. (2018). Projeto Teresina Mais Verde ultrapassa todos os projetos de Arborização da Cidade. http://www.portalpmt.teresina.pi.gov.br/noticia/Projeto-Teresina-MaisVerde-ultrapassatodos-os-projetos-de-Arborizacao-da-Cidade/11699.

Reis, S. M., Marimon-Júnior, B. H., Morandi, P. S., Oliveira-Santos, C., Oliveira, B., \& Marimon, B. S. (2016). Desenvolvimento inicial e qualidade de mudas de Copaifera langsdorffii desf. sob diferentes níveis de sombreamento. Ciência Florestal, 26(1), 11-20.

Robba, F., \& Macedo, S. S. (2002). Praças Brasileiras. EDUSP. 
Research, Society and Development, v. 11, n. 2, e22111225475, 2022 (CC BY 4.0) | ISSN 2525-3409 | DOI: http://dx.doi.org/10.33448/rsd-v11i2.25475

Rodrigues, C. \& Blasttmann, U. (2014). Gestão da informação e a importância do uso de fontes de informação para geração de conhecimento. Perspectivas em Ciências da Informação, 19(3), 2-29.

Rodrigues, C. A. G. et al. (2002). Arborização urbana e produção de mudas de essências florestais nativas em Corumbá, MS / Corumbá: Embrapa Pantanal.

Schuch, M. I. S. (2006). Arborização Urbana: uma contribuição à qualidade de vida com uso de geotecnologia. Dissertação (mestrado em geomática) Universidade Federal de Santa Maria - RS.

Scremin-Dias, E. (2006). Produção de mudas de espécies florestais nativas: manual. Ed. UFMS. 59p.

Silva, J. V. L., \& Silveira, R. L. L. (2020). Urbanização, Planejamento e Arborização: uma análise da cidade de Santa Cruz Do Sul/RS. Colóquio - Revista do Desenvolvimento Regional, 17(1), 161-180.

Souza J. R., \& Melo, C. A. S. M. (2014). Os parques urbanos como indicadores de qualidade de vida: análise dos parques urbanos de Uberlândia-MG. Periód Téc Científ Cidades Verdes., 2(3), 68-85.

Torres, M. et al. (2013). Saúde e bem-estar em meio urbano: das políticas à prática. Revista Port. Saúde Pública. 31(1), 95-107.

Viana, A. I. G., \& Lima, I. M. M. F. (2017). Parques ambientais urbanos de Teresina, Piauí: ambiente, conservação e uso pela população local. In: XVII Simpósio Brasileiro Geografia $\quad$ de Física Aplicada, Campinashttps://www.researchgate.net/publication/323323875_Parques_ambientais_urbanos_de_Teresina_Piaui_ambiente_conservacao_e_uso_pela_populacao_local.

Villela, F. A., \& Menezes, N. L. (2009). O Potencial de Armazenamento de Cada Semente. Seed News, Ano XIII, n.3, 2009.

Xanxerê. Secretaria de Políticas Ambientais. (2009). Manual da Arborização Urbana de Xanxerê. Xanxerê: Secretaria Municipal. 20p. 